\title{
DISTRIBUSI DAN PEMETAAN JENIS-JENIS KARYA SASTRA YANG TUMBUH DAN BERKEMBANG PADA MASYARAKAT TUTUR BAHASA JAWA DI PULAU LOMBOK
}

\author{
Nuryati ${ }^{*}$
}

\begin{abstract}
Abstrak
Karya sastra suatu tutur bahasa tertentu akan berkembang seiring dengan perkembangan bahasa itu, sebab bahasa merupakan medium realisasi karya sastra. Perkembangan suatu karya sastra dapat dipengaruhi oleh beberapa faktor, salah satunya adalah migrasi atau perpindahan masyarakat tutur suatu bahasa ke suatu daerah yang jauh dari daerah asalnya. Selain itu, kontak dengan masyarakat tutur bahasa lain di tempat yang baru akan berpengaruh pada keberadaan dan corak dari sastra yang berkembang di tempat yang baru. Tujuan penelitian ini adalah mendeskripsikan bentuk dan jenis-jenis karya sastra yang hidup pada masyarakat tutur bahasa Jawa di Pulau Lombok.
\end{abstract}

Kata kunci : Puisi, legenda, mite, dongeng

\section{Pengantar}

Bahasa Jawa merupakan salah satu bahasa daerah yang mempunyai penutur cukup banyak, sehingga keberadaan etnis Jawa dengan bahasa Jawanya menyebar tidak hanya di Pulau Jawa, tetapi juga tersebar di wilayah-wilayah di luar Pulau Jawa.(Koentjaraningrat, 1984).

Kedatangan etnis Jawa khusunya di Pulau Lombok dan Sumbawa diduga terjadi sejak abad ke-14 bersamaan dengan masuknya pengaruh Kerajaan Majapahit. Pada umumnya, orang Jawa, khususnya para petani Jawa mempunyai persepsi waktu yang sangat tajam dan bahkan memiliki cara-cara yang rumit untuk menentukan waktu. Misalnya, bagaimana

\footnotetext{
*) Sarjana Pendidikan, Pembantu Pimpinan pada Kantor Bahasa Prov. NTB
} 
orang Jawa menggunakan berbagai sistem penanggalan untuk berbagai tujuan dan bagaimana berbagai metode yang rumit untuk mengombinasikan berbagai sistem penanggalan itu untuk menentukan tanggal-tanggal yang baik secara religio-magi, guna memulai suatu pekerjaan yang penting.

Kemudian, hal yang sangat menonjol dalam cara berpikir etnis Jawa adalah perasaan bahwa orang tidak berada sendiri di dunia dan bahwa ia selalu dapat mengharapkan bantuan dari sesamanya, terutama para kaum kerabatnya, yang sebaliknya juga mengharapkan hal yang sama dari mereka. Dengan demikian, ia wajib menjaga hubungan baik dengan mereka dan para tetangga dekatnya, dengan senantiasa memperhatikan kebutuhan mereka, sebanyak mungkin membagi miliknya dengan mereka dan sebanyak mungkin berusaha menempatkan dirinya pada keadaan mereka, yaitu bertenggang rasa dengan mereka, sehingga ada pula istilah "biar tidak makan asal bisa berkumpul". (Koentjaraningrat, 1984)

Dari uraian di atas, maka dapat dilihat bahwa kemungkinan besar, di mana pun orang Jawa itu berada, mereka akan tetap mempertahankan budaya mereka sendiri. Begitu pula dengan bahasanya, meskipun ada kemungkinan bahasa yang digunakannya itu telah terpengaruh oleh bahasa-bahasa lain yang ada di sekitarnya, tapi mereka tetap menggunakannya dan setia terhadap bahasa mereka sendiri. Penelitian tentang hal tersebut telah dilakukan oleh Hartini dengan judul Distribusi dan Pemetaan Varian-Varian Bahasa Jawa di Nusa Tenggara Barat (2005). Masih kuatnya etnis Jawa mempertahankan ciri khas ini menyebabkab keberadaan etnis Jawa ke Pulau Lombok sedikit banyak berpengaruh pada prilaku etnis Sasak secara umum. Tidak heran 
kemudian kebudayan, khususnya khazanah kesusastraan Sasak banyak yang sama dengan kesastraan Jawa. Tidak hanya itu, dari khazanah kuliner sampai ke system tata tulis Sasak juga banyak dipengaruhi oleh Jawa.

Pada setiap keragaman suatu masyarakat tutur bahasa mempunyai karya sastra yang tercipta oleh masyarakat tersebut. Karya sastra suatu masyarakat bahasa tertentu disebut sebagai sastra daerah yang sekaligus merupakan kekayaan sastra nusantara.

Sehubungan dengan itu, masyarakat Jawa yang tinggal di wilayah Lombok yang bukan daerah induknya diasumsikan masih mempertahankan sastranya pula karena bahasa yang menjadi medium sastra itu masih terpelihara.

Penelitian ini mencoba mendiskripsikan dan menginventarisasikan bentuk dan jenis karya sastra yang hidup dalam komunitas masyarakat tutur bahasa Jawa di Pulau Lombok yang berupa sastra lisan maupun sastra tulis tradisional.

Keberadaan sastra daerah yang merupakan kekayaan kazanah budaya bangsa ini menjadi sangat penting agar tidak hilang karena sudah tidak dipakai atau dilestarikan oleh masyarakat penuturnya. Untuk itu perlu dilakukan usaha yang nyata dalam rangka pendokumentasian bentuk-bentuk dan jenis-jenis sastra daerah yang ada di seluruh nusantara.

Penelitian ini dilakukan dengan tujuan : (a)mendiskripsikan bentuk dan jenis karya sastra yang hidup dan berkembang pada masyarakat tutur bahasa Jawa di Pulau Lombok; (b) mendiskripsikan wilayah sebaran geografis bentuk dan jenis-jenis sastra tersebut di masing-masing wilayah penutur bahasa Jawa di Pulau Lombok; dan (c) 
mendiskripsikan kondisi masyarakat pendukung dan penikmat bentuk dan jenis-jenis karya sastra tersebut di wilayah penutur bahasa Jawa di Pulau Lombok.

Pengertian bentuk sastra yang digunakan dalam penelitian ini adalah sama dengan pengertian ragam sastra seperti yang disebut dalam Kamus Sastra oleh Sudjiman, Panuti (1990) . Ragam sastra merujuk ke jenis karya sastra yang memiliki bentuk, teknik, atau isi yang khusus. Ragam sastra meliputi ragam puisi, prosa, dan drama.

Sedangkan pengertian jenis karya sastra atau disebut juga cipta sastra dalam penelitian ini adalah jenis sastra yang mengacu kepada macam karangan yang memiliki bentuk, teknik, atau isi yang tetap dalam suatu ragam sastra. Seperti misalnya ragam puisi memiliki jenis seperti pantun, syair, dll.

Pengertian distribusi yang dikaitkan dengan sastra adalah persebaran suatu karya sastra masyarakat tutur bahasa tertentu di wilayah geografis tertentu pula. Bentuk sastra adalah ragam sastra yang dimiliki, tumbuh dan berkembang pada masyrakat tutur tersebut, sedangkan jenis sastra adalah bagian-bagian dari bentuk sastra yang kemudian disebut juga cipta sastra.

Teori yang yang digunakan sebagai dasar dalam klasifikasi karya sastra genre prosa adalah pendapat dari William R. Bascom (Dananjaya, 1991 : 50), cerita prosa rakyat dapat dibagi dalam tiga golongan besar, yaitu 1) mite (myth), legenda (legend), dan 3) dongeng (folktale).

Jan Harold Brunand menggolongkan legenda menjadi empat kelompok,yaitu 1) legenda keagamaan (religious legends), 2) legenda alam gaib (supernatural legends), 3) legenda perseorangan (personal legends), dan 4) legenda setempat (local legends). 
Teknik analisis data yang digunakan dalan penelitian ini sebagai berikut:

Data

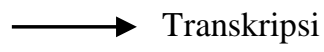
Terjemahan

Klasifikasi dalam ragam sastra $\longrightarrow$ Klasifikasi dalam jenis cipta sastra Analisis tiap jenis cipta sastra

\section{Pembahasan}

\section{Daerah Pengamatan Praya}

Praya merupakan Ibukota Kabupaten Lombok Tengah. Sebagai ibukota, Praya menjadi pusat kegiatan perekonomian serta administrasi pemerintahan. Wilayah Praya mempunyai struktur tanah yang cukup subur sehingga kegiatan di sektor pertanian masih lebih besar di bandingkan kegiatan di sektor perdagangan dan jasa. Desa/Kelurahan Praya sebagai salah satu desa yang berada di Kecamatan Praya, Kabupaten Lombok Tengah, Nusa Tenggara Barat telah berdiri sejak zaman Belanda.

Salah satu kampung di Desa Praya ini mayoritas penduduknya adalah etnis Jawa, sehingga nama kampungnya pun diberi nama Kampung Jawa. Menurut data statistik Hasil Sensus Penduduk 2000 yang dilakukan oleh Badan Statistik Provinsi Nusa Tenggara Barat jumlah suku Jawa yang tinggal di wilayah Lombok Tengah adalah 2.523 jiwa. Khusus di di Kecamatan Praya sendiri jumlah suku Jawa sekitar 1.728 jiwa. Penduduk Jawa yang pindah ke Desa Praya ini berawal dari satu keluarga yang datang dari Pulau Jawa dengan maksud untuk mengadu nasib dengan cara berdagang dan menempati satu tempat yang dianggapnya ramai. Seiring dengan berjalannya waktu, usaha berdagang 
dianggap dapat mencukupi kebutuhan keluarga sehingga ada keluarga lain yang datang untuk usaha yang sama dan menempati wilayah yang sama. Lambat laun, kampung tersebut dipenuhi dengan orang-orang jawa dan semenjak itu kampung tersebut diberi nama kampung Jawa. Ratarata mereka berasal dari Jawa Timur dan sebagian lagi dari Jawa Tengah. Tidak hanya itu, sekitar tahun 1980-an, Desa Praya pernah mendatangkan guru-guru yang berasal dari Yogyakarta karena pada saat itu, Desa praya sedang kekurangan tenaga guru di sekolah-sekolah menengah khususnya Sekolah Menengah Tingkat Pertama yang selanjutnya para guru itu tinggal menetap di Desa tersebut..

Tabel 1. Data Ragam Sastra di Daerah Pengamatan Desa Praya

\begin{tabular}{|c|c|c|c|}
\hline No & Ragam Sastra & $\begin{array}{l}\text { Jenis/Cipta } \\
\text { Sastra }\end{array}$ & Diskripsi Data yang ditemukan \\
\hline \multirow[t]{3}{*}{1} & \multirow[t]{3}{*}{$\begin{array}{l}\text { Puisi } \\
\text { (Geguritan) }\end{array}$} & $\begin{array}{l}\text { Geguritan } \\
\text { dalam tembang: }\end{array}$ & \\
\hline & & Dijil & $\begin{array}{l}\text { Puisi tentang nasehat orangtua kepada } \\
\text { anaknya dalam memilih kebaikan } \\
\text { dalam hidup } \\
\text { Ndek dalane guna lawan sakti } \\
\text { Kudu andap asor } \\
\text { Wani ngalah dhuwur wekasane } \\
\text { Tumungkulo yen dipun dukani } \\
\text { Bapak den simpangi } \\
\text { Ana catur mungkur }\end{array}$ \\
\hline & & 口 Kinanti & $\begin{array}{l}\text { Puisi tentang nasehat kepada para } \\
\text { petani memilih waktu untuk memulai } \\
\text { menanam padi } \\
\text { Pra bapak tani den emut } \\
\text { Ojo padha gugub yekti } \\
\text { Durung mangsa nira nyebar } \\
\text { Entenana wektu nuli } \\
\text { Udan tumurun saknyata } \\
\text { Tumiba ana ing bumi }\end{array}$ \\
\hline
\end{tabular}


Distribusi Dan Pemetaan Jenis-Jenis Karya Sastra...

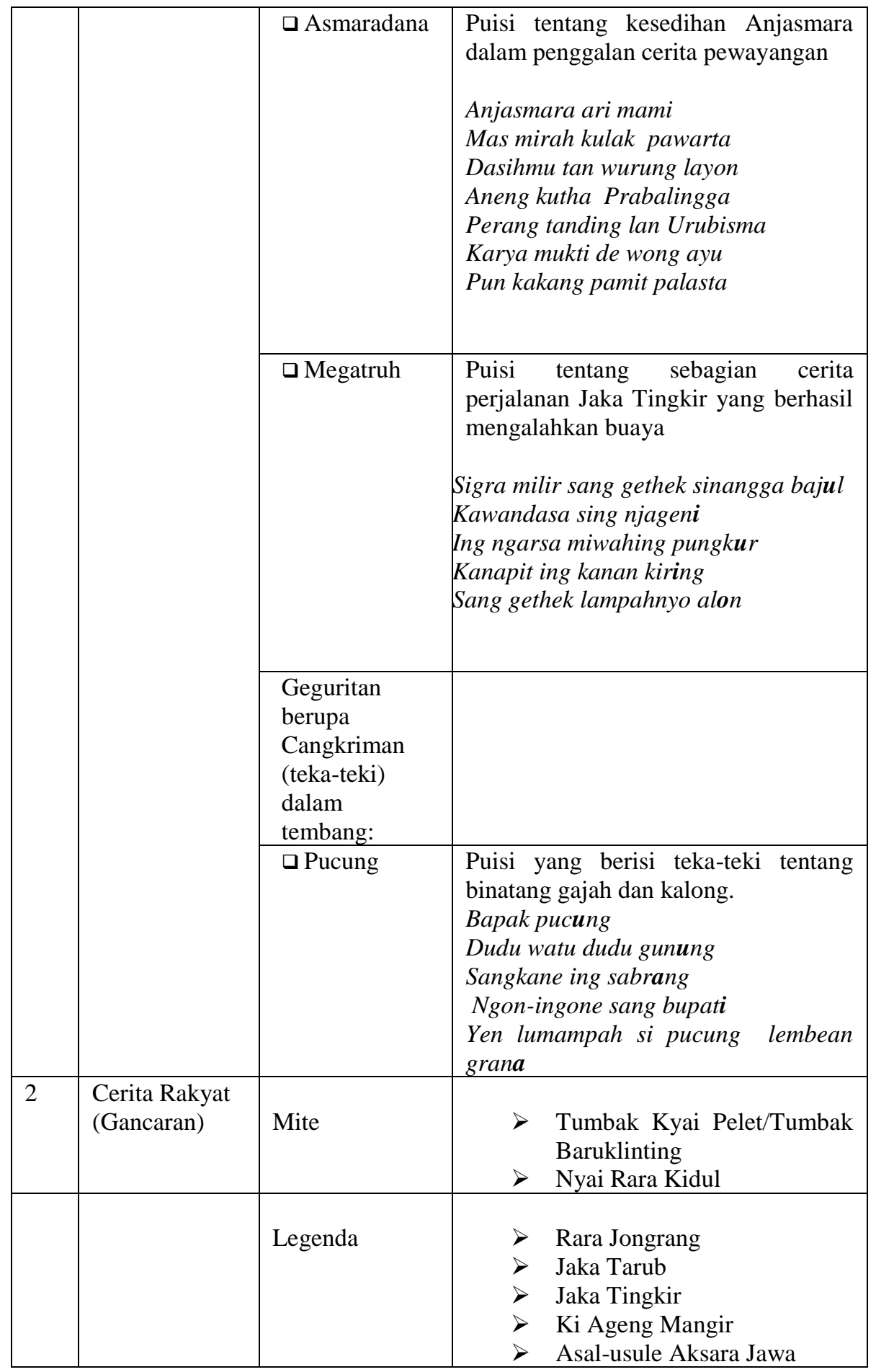




\subsection{Daerah Pengamatan Sakra}

Desa Sakra merupakan salah satu desa yang berada di Kecamatan Sakra. Pada saat ini, Kecamatan Sakra sudah mengalami pemekaran menjadi tiga kecamatan yakni Kecamatan Sakra, Sakra Barat, dan Sakra Timur yang memiliki wilayah seluas 24,77 km2. Penduduk desa Sakra terdiri atas beraneka ragam suku, misalnya Suku Sasak, Sumbawa, Bali dan Jawa. Menurut data statistik Hasil Sensus Penduduk 2000 yang dilakukan oleh Badan Statistik Provinsi Nusa Tenggara Barat menunjukkan jumlah suku Jawa yang tinggal di wilayah Lombok Timur adalah 4.597 jiwa.

Mata pencahariannya pun beraneka ragam mulai dari bertani, berdagang, buruh, dan pegawai. Pada umumnya, masyarakat Jawa yang datang ke desa ini berniat untuk berdagang. Karena keuletannya, wajar saja jika semakin hari apa yang mereka jual itu semakin maju pesat sehingga banyak keluarga atau teman yang mengikuti jejaknya untuk datang. Akhirnya, jadilah desa tersebut didominasi oleh orang-orang Jawa yang telah berkeluarga dan tinggal menetap. Selain itu, ada juga orang-orang Jawa yang datang ke desa ini karena tugas kedinasan.

Tabel 2 Data Ragam Sastra di Daerah Pengamatan Desa Sakra

\begin{tabular}{|c|c|c|c|}
\hline No & $\begin{array}{c}\text { Ragam } \\
\text { Sastra }\end{array}$ & Jenis & Diskripsi Data \\
\hline 1 & Puisi & Syair Tembang & $\begin{array}{l}\text { Syair bahasa Jawa halus atau madya yang } \\
\text { dinyanyikan dengan iringan alat musik } \\
\text { tradisional.Kelompok nyanyi ini biasa } \\
\text { dipentaskan dalam acara hajatan orang-orang } \\
\text { Jawa sebagai upaya pelestarian budaya dan } \\
\text { sebagai hiburan. Pada umumnya terdiri dari } \\
\text { penabuh gamelan atau alat musik lain dan } \\
\text { penyanyi. }\end{array}$ \\
\hline
\end{tabular}


Distribusi Dan Pemetaan Jenis-Jenis Karya Sastra...

\begin{tabular}{|c|c|c|c|}
\hline 2 & $\begin{array}{l}\text { Cerita } \\
\text { Rakyat }\end{array}$ & Mite & $\begin{array}{ll}> & \text { Tumbak Kyai Pleret/Tumbak Baruklinting } \\
& \text { Nyai Rara Kidul }\end{array}$ \\
\hline & & Legenda & $\begin{array}{ll}> & \text { Rara Jongrang } \\
> & \text { Jaka Tarub } \\
> & \text { Ki Ageng Mangir } \\
> & \text { Sangkuriang } \\
> & \text { Siung Wanara }\end{array}$ \\
\hline & & $\begin{array}{l}\text { Dongeng: } \\
\text { Dongeng } \\
\text { Binatang/Fabel }\end{array}$ & $\begin{array}{l}>\text { Andhe-Ande Lumut } \\
>\text { Si Gagak Putih lan Gagak Ireng } \\
>\text { Si Kancil Nyolong Timun } \\
>\text { Si Kancil lan Keong }\end{array}$ \\
\hline
\end{tabular}

\subsection{Wilayah Komunitas Sastra Jawa yang Inovatif dan Konservtif}

Pengertian Inovatif dalam penelitian sastra ini adalah terjadinya proses inovasi dalam ragam dan jenis cipta sastra tertentu yang bisa berupa penghilangan, perubahan, dan pembaruan. Adapaun pengertian Konservatif dalam penelitian sastra ini adalah sikap pemertahanan suatu ragam/jenis cipta sastra oleh suatu komunitas tertentu. Pemertahanan ragam/jenis cipta sastra ini bisa ditinjau secara kualititaf maupun kuantitatif

Dari dua daerah pengamatan pada penelitian ini wilayah komunitas sastra Jawa yang inovatif adalah daerah pengamatan Desa Sakra. Hal ini didukung data yang diperoleh dari daerah pengamatan tersebut yang menunjukkan bahwa secara kuantitaf pemertahanan ragam dan jenis cipta sastra lebih sedikit dibanding daerah pengamatan Desa Praya. Meskipun demikian, data dari daerah pengamatan Desa Sakra secara kualitatif masih menunjukkan bahwa ragam prosa cerita rakyat pada judul tertentu secara tokoh, alur cerita, settingnya relatif sama dengan sastra di daerah induk.

Data-data yang menunjukkan adanya proses inovasi yang berupa hilangnya jenis cipta sastra tersebut secara kuantitatif adalah tidak 
ditemukannya ragam sastra geguritan jenis cipta sastra dalam tembang Mijil, Kinanti, Asmaradana, Megatruh, dan Pucung seperti yang ditemukan di daerah pengamatan desa Praya. Proses inovasi yang ditemukan berupa hilangnya ragam sastra saja, sedangkan proses inovasi yang bermakna munculnya ragam atau jenis cipta sastra juga tidak ditemukan.

Sedangkan data yang berupa ragam sastra prosa di daerah Sakra lebih banyak secara kuantitas namun secara kualitas meliputi alur, nama tokoh cerita dan settingnya relatif tidak sama seperti di daerah pengamatan desa Praya dan daerah induknya. Hal tersebut dapat diketahui dari data-data seperti berikut:

\begin{tabular}{|l|l|l|}
\hline No. & Jenis Cipta Sastra dan Judul & \multicolumn{1}{c|}{ Keterangan } \\
\hline 1 & Mite : Tumbak Baruklinting & $\begin{array}{l}\text { Secara alur cerita relatif sama dengan data } \\
\text { dari daerah pengamatan Praya dan dengan } \\
\text { daerah induknya hanya tidak menyebutkan } \\
\text { nama tokoh cerita secara lengkap dan begitu } \\
\text { juga dengan settingnya }\end{array}$ \\
\hline 2 & Mite : Nyai Rara Kidul & $\begin{array}{l}\text { Secara alur cerita dan nama tokoh relatif } \\
\text { tidak sama dengan data pengamatan desa } \\
\text { Praya namun relatif sama dengan cerita } \\
\text { yang berkembang di daerah induk. }\end{array}$ \\
\hline 3 & Legenda: Rara Jonggrang & $\begin{array}{l}\text { Secara alur cerita dan nama tokoh relatif } \\
\text { sama dengan data pengamatan desa Praya } \\
\text { dan daerah induk, namun settingnya tidak } \\
\text { menyebut nama kerajaan Pengging seperti } \\
\text { data dari daerah pengamatan desa Praya }\end{array}$ \\
\hline 4 & Legenda: Ki Ageng Mangir & $\begin{array}{l}\text { Alur cerita secara garis besar relatif sama } \\
\text { dengan data dari daerah pengamatan desa } \\
\text { Praya dan juga daerah induk. Namun nama } \\
\text { tokoh dan setting dalam cerita tersebut tidak } \\
\text { lengkap seperti data dari daerah pengamatan } \\
\text { desa Praya. Data yang diperoleh hanya } \\
\text { menyebut seorang putri, seorang raja, dan } \\
\text { penasehat kerajaan untuk menyebutkan } \\
\text { nama Putri Pembayun, Panembahan }\end{array}$ \\
\hline
\end{tabular}




\begin{tabular}{|l|l|l|}
\hline & & $\begin{array}{l}\text { Senopati, Ki Juru Mertani. Sedangkan untuk } \\
\text { setting nama kerajaan tidak menyebutkan } \\
\text { kerajaan Mataram seperti data dari daerah } \\
\text { pengamatan desa Praya dan daerah } \\
\text { induknya. }\end{array}$ \\
\hline 5 & Legenda: Jaka Tarub & $\begin{array}{l}\text { Alur cerita relatif sama dengan data yang } \\
\text { diperoleh dari daerah pengamatan desa } \\
\text { Praya dan daerah induknya. Namun data } \\
\text { dari daerah pengamatan desa Sakra hanya } \\
\text { menyebutkan nama tokoh Jaka Tarub } \\
\text { sedangkan nama-nama tokoh yang lain } \\
\text { tidak disebutkan seperti Dewi Nawang } \\
\text { Wulan bidadari yang menjadi istrinya, Ni } \\
\text { Tarub yaitu ibunya Jaka Tarub. }\end{array}$ \\
\hline 6 & Dongeng:Andhe-Andhe Lumut \\
& & $\begin{array}{l}\text { Data yang diperoleh menunjukkan bahwa } \\
\text { alur cerita dan setting cerita tersebut relatif } \\
\text { sama dengan data yang diperoleh dari } \\
\text { daerah pengamatan desa Praya dan juga } \\
\text { daerah induk. Namun data tidak } \\
\text { menyebutkan nama-nama tokoh seperti } \\
\text { Mbok Rondo ibunya tiga gadis itu dan juga } \\
\text { tokoh dewa Bango Tongtong yang selalu } \\
\text { membantu Kleting Kuning. }\end{array}$ \\
\hline
\end{tabular}

Sementara itu daerah yang pengamatan Praya merupakan daerah yang konservatif. Data-data yang diperoleh dari daerah pengamatan Desa Praya telah menunjukkan tingkat pemertahanan karya sastra Jawa lebig tinggi dibandingkan dengan daerah pengamatan Sakra. Pemertahanan secara kualitatif dapat terlihat dari kesamaan nama tokoh, alur cerita, dan setingnya untuk ragam prosa. Untuk ragam puisi diperoleh data bahwa puisi-puisi tersebut masih tetap mematuhi pakem atau kaidah puisi dari daerah induk.

Pemertahanan secara kuantitatif ditunjukkan dari data bahwa ragam sastra berupa prosa dan puisi serta jenis cipta sastra yang ditemukan ini menunjukkan lebih banyak. Sebenarnya ragam dan jenis 
cipta sastra di daerah induk ada yang tidak ditemukan lagi di daerah pengamatan ini tapi secara kuantitas ragam dan jenis cipta sastra di daerah pengamatan Desa Praya ini lebih banyak dibanding daerah pengamatan Desa Sakra.

\subsection{Peta Sebaran Geografis Jenis Cipta Sastra pada daerah}

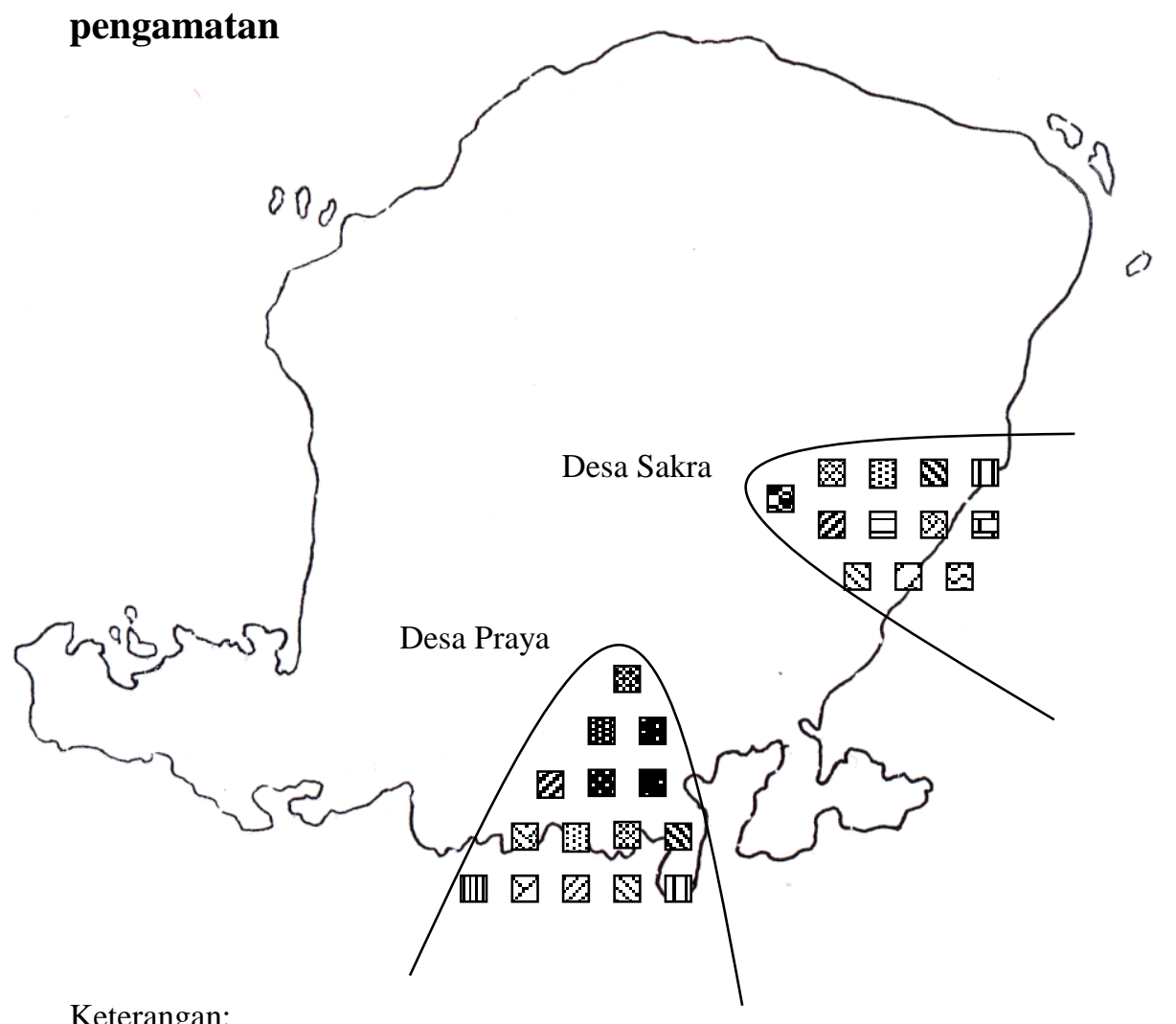

Keterangan:

Ragam Sastra Puisi (Geguritan):

原

: Jenis Cipta Sastra Tembang Mijil

聞

: Jenis Cipta Sastra Tembang Kinanti

$\because$

: Jenis Cipta Sastra Tembang Asmaradana

$::$

: Jenis Cipta Sastra Tembang Megatruh

.

: Jenis Cipta Sastra Tembang Pucung 
: Jenis Cipta Sastra Syair Tembang

Ragam Sastra Prosa (Gancaran):

国: Mite Judul Tumbak Baruklinting/Kyai Pelet

: Mite Judul Nyai Rara Kidul

: Legenda Judul Rara Jongrang

: Legenda Judul Jaka Tarub

: Legenda Judul Jaka Tingkir

: Legenda Judul Ki Ageng Mangir

ए : Legenda Judul Sangkuriang

IIII : Legenda Judul Asal-Usule Aksara Jawa

曰 $\quad$ : Legenda Judul Siyung Wanara

: Dongeng Judul Andhe-Andhe Lumut

回 : Dongeng Judul Si Gagak Putih lan Ireng

: Dongeng Judul Si Kancil Nyolong Timun

6 : Dongeng Judul Si Kancil lan Keong

\section{Kesimpulan dan Saran}

\subsection{Simpulan}

Dari dua daerah pengamatan yang dijadikan penelitian tentang distribusi dan persebaran bentuk dan jenis karya sastra pada masyarakat tutur bahasa Jawa di Pulau Lombok ini menunjukkan bahwa masyarakat masih mengetahui bentuk dan jenis karya sastra Jawa dari daerah induk atau asalnya. Data yang diperoleh dari dua daerah pengamatan menunjukkan perbedaan secara kualitas dan kuantitas dari daerah induknya sehingga dapat dikatakan bahwa dalam distribusi dan 
persebaran bentuk dan jenis karya sastra tersebut telah mengalami proses inovasi. Proses inovasi itu sendiri mempunyai pengertian telah berupa perubahan dalam bentuk penghilangan atau pembaharuan. Proses inovasi itu lebih banyak ditemukan di daerah pengamatan Desa Sakra, hal itu dapat dilihat bahwa secara kualitatif bentuk dan jenis karya sastra yang ditemukan relatif tidak sama dengan di daerah induk. Apabila ditinjau dari segi kuantitif maka jumlah bentuk dan jenis karya sastra yang ditemukan lebih sedikit.

Sedangkan daerah pengamatan desa Praya menunjukkan adanya proses konservatif yaitu pemertahanan terhadap bentuk dan jenis karya sastra sesuai dengan daerah asal atau induknya. Pemertahanan terhadap bentuk dan jenis karya sastra ini dapat ditinjau secara kualitatif yaitu masih terdapat relatif kesamaan dari daerah induk dan kuantitatif yaitu jumlah bentuk dan jenis karya sastra yang ada.

\subsection{Saran}

Setiap masyarakat tutur suatu bahasa mempunyai sastra sebagai identitas dan cerminan pandangan hidup masyarakat itu sendiri. Meskipun masyarakat tutur tersebut telah tinggal menetap jauh dari daerah induk atau asal sebaiknya tetap berusaha menjaga tradisi sastra yang ada dengan membentuk suatu organisasi atau lembaga yang berorientasi pada seni dan budayanya. Seperti halnya dengan masyarakat tutur bahasa Jawa yang berada di Pulau Lombok ini apabila tidak memiliki pola pewarisan tradisi kesastraan yang sekarang masih ada maka lambat laun eksistensi sastra Jawa akan tenggelam di tengah kehidupan sosial yang beragam. 


\section{DAFTAR PUSTAKA}

Dananjaja, James. 2001. Foklor Indonesia: Ilmu Gosip, Dongeng, dan lain- lain. Jakarta: Pustaka Utama Grafiti.

Darma, Budi. 2004. Pengantar Teori Sastra. Jakarta: Pusat Bahasa.

Darusuprapta. 1985. Serat Wulang Reh. Surabaya: CV. Citra Jaya

Diyono. Tuntunan Lengkap Sekar Macapat Untuk Pelajar dan Umum. Surakarta. CV. Cendrawasih.

Hartini. 2006. Penelitian Mandiri: Distribusi dan Pemetaan Varianvarian Bahasa Jawa di NTB. Mataram: Kantor Bahasa Provinsi NTB.

Haryatmo, Sri, dkk. 2003. Macapat Modern Dalam Sastra Jawa: Analisis Bentuk dan Isi. Jakarta: Pusat Bahasa.

Jabrohim (Ed.). 2003. Metodologi Penelitian Sastra. Yogyakarta: Hanindita Graha Widya.

Koentjaraningrat. 1984. Kebudayaan Jawa. Jakarta: Balai Pustaka.

Mardiyanto. 2005. Cerita Rakyat Boyolali (Transkripsi dan Terjemahan). Jakarta: Pusat Bahasa.

Purwadi. 2007. Sejarah Sastra Jawa. Yogyakarta: Panji Pustaka Yogyakarta.

Prabowo, Dhanu Priyo. 2004. Antologi Cerita Rakyat Daerah Istimewa Yogyakarta. Jakarta: Pusat Bahasa.

Sudjiman, Panuti. 1990. Kamus Istilah Sastra. Jakarta: Penerbit Universitas Indonesia.

Tirtawidjaya, Yohani HT, dkk. 1979. Sastra Lisan Jawa. Jakarta: Pusat Pembinaan dan Pengembangan Bahasa Departemen Pendidikan dan Kebudayaan. 